\title{
STEM-EDS Analysis of Fission Products in Neutron-Irradiated TRISO Fuel Particles from AGR-1 Experiment
}

\author{
B. Leng, ${ }^{\text {a,b }}$ I.J. van Rooyen, ${ }^{c}$ Y.Q. Wu, ${ }^{\text {de }}$ I. Szlufarska, ${ }^{a}$ K. Sridharan ${ }^{\text {a }}$ \\ ${ }^{a}$ University of Wisconsin-Madison, Madison, WI 53706, USA \\ ${ }^{b}$ Thorium Molten Salts Reactor Center, Shanghai Institute of Applied Physics, Shanghai 201800, China \\ ${ }^{c}$ Fuel Design and Development Department, Idaho National Laboratory, \\ Idaho Falls, ID 83415-6188, USA \\ ${ }^{d}$ Department of Materials Science and Engineering, Boise State University, \\ Boise, ID 83725-2090, USA \\ ${ }^{e}$ Center for Advanced Energy Studies, Idaho Falls, ID 83401, USA
}

\begin{abstract}
Historic and recent post-irradiation-examination from the German AVR and Advanced Gas Reactor Fuel Development and Qualification Project have shown that $110 \mathrm{~m} \mathrm{Ag}$ is released from intact tristructural isotropic (TRISO) fuel. Although TRISO fuel particle research has been performed over the last few decades, little is known about how metallic fission products are transported through the SiC layer, and it was not until March 2013 that Ag was first identified in the SiC layer of a neutron-irradiated TRISO fuel particle. The existence of $\mathrm{Pd}$ - and Ag-rich grain boundary precipitates, triple junction precipitates, and $\mathrm{Pd}$ nano-sized intragranular precipitates in neutron-irradiated TRISO particle coatings was investigated using Scanning Transmission Electron Microscopy and Energy Dispersive Spectroscopy analysis to obtain more information on the chemical composition of the fission product precipitates. A U-rich fission product honeycomb shape precipitate network was found near a micron-sized precipitate in a $\mathrm{SiC}$ grain about $\sim 5 \mu \mathrm{m}$ from the $\mathrm{SiC}$-inner pyrolytic carbon interlayer, indicating a possible intragranular transport path for uranium. A single Ag-Pd nano-sized precipitate was found inside a $\mathrm{SiC}$ grain, and this is the first research showing such finding in irradiated $\mathrm{SiC}$. This finding may possibly suggest a possible Pd-assisted intragranular transport mechanism for $\mathrm{Ag}$ and may be related to void or dislocation networks inside $\mathrm{SiC}$ grains. Preliminary semi-quantitative analysis indicated the micron-sized precipitates to be $\mathrm{Pd}_{2} \mathrm{Si}_{2} \mathrm{U}$ with carbon existing inside these precipitates. However, the results of such analysis for nano-sized precipitates may be influenced by the $\mathrm{SiC}$ matrix. The results reported in this paper confirm the co-existence of $\mathrm{Cd}$ with Ag in triple points reported previously.
\end{abstract}

Corresponding author: I.J. van Rooyen, Isabella.vanrooven@inl.gov, +12085264199

\section{INTRODUCTION}

Tristructural isotropic (TRISO) coated particle fuel is currently used in high temperature gas-cooled reactors and will be the fuel of choice for the Generation IV Very High Temperature Reactor [1]. However, for its successful use in Very High Temperature Reactor, release mechanisms of metallic fission products (FPs), such as Ag and Pd through TRISO particles' coatings, should be clearly understood and eventually quantified $[2,3]$.

Release of Ag from TRISO particles is of most concern from the standpoint of personnel safety issues during maintenance. Many reactor experiments [2,4,5], out-of-pile surrogate experiments [6-9], and modelling studies $[10,11]$ have been performed to understand the possible release mechanism of Ag. Grain boundary (GB) diffusion [7-11] and vapor release through micro-cracks [6] have been proposed, 
but none of these mechanisms conclusively explain the release from individual coated particles of up to $100 \%$ of the produced Ag observed in in-reactor TRISO particle irradiation tests. However, it should be noted that each compact contained over 4,000 coated particles, and the average fraction of Ag release in each Advanced Gas Reactor (AGR)-1 capsule (four compacts) ranged from 1.2 × 10-2 to $3.8 \times 10-1$ (a fraction of $2.0 \times 10-5$ is equivalent to $100 \%$ release from a single particle) [3]. Palladium is also a metallic FP of great interest in TRISO fuel. Past studies have shown that Pd can corrode SiC [12,15] and will potentially cause failure of the fuel particle. Furthermore, these experiments also suggest that Pd can potentially assist the transport of other FP such as Ag [16] and U [12] by forming Pd-FP silicides nodules, which can move along grain boundaries.

The examination of FP in neutron-irradiated TRISO coated particles is important and the results can provide insight into FP transport mechanisms proposed and investigated in out-of-pile surrogate experiments. Nano-scale analysis of FP in TRISO particles' coatings has only recently received attention due in large part to the availability of nano-scale analytical tools in facilities where neutron irradiated fuels could be handled, prepared, and analyzed, as well as the availability of neutron irradiated UCO contained fuel particles with known irradiation histories.

Incorporating Scanning Transmission Electron Microscopy (STEM) and Energy Dispersive Spectroscopy (EDS) analysis together is an excellent way for providing new insights into FP transport. A previous study by van Rooyen et al. [4] has demonstrated this by identification of Ag for the first time in neutron irradiated TRISO fuel particles with this technique. This study qualitatively examined FP precipitates in the SiC-inner pyrolytical carbon (IPyC) interlayer and focused specifically on the identification of $\mathrm{Ag}, \mathrm{Pd}$, $\mathrm{U}$, and $\mathrm{Cd}$ in selected areas. In the present study, the work by van Rooyen et al. [4] has been extended to examine FP precipitates inside the $\mathrm{SiC}$ layer $(0.5 \mu \mathrm{m}$ to $5 \mu \mathrm{m}$ from the SiC-IPyC interlayer), along with a quantitative assessment of size, shape, preferential location, and composition of those FP precipitates by STEM-EDS.

\section{MATERIALS AND METHODS}

The TRISO fuel particle examined in this study was CP35 from Compact 6-3-2 from the AGR-1 experiment, which had an estimated Ag retention of $80 \%$. The retention of $110 \mathrm{mAg}$ is estimated by comparing the measured inventory to the predicted inventory normalized by the relative Cs-137 activity to reduce the influence of different kernel sizes on the overall distribution. This particle was therefore chosen for electron microscopy examination, as the particle therefore exhibits good Ag retention characteristics. This study is therefore the continuation in a larger battery of experiments of the AGR program, to identify particle, or more specifically the $\mathrm{SiC}$ layer; characteristics that can provide more information on the varying release of Ag within coated particles from the same compact. Details of this fuel particle and the rationale for its selection for this study are further described elsewhere [3, 4]. Two STEM lamellae (identified as $6 \mathrm{a}$ and $6 \mathrm{~b}$ ) were prepared by a focused ion beam near the IPyC-SiC interlayer as shown in Fig. 1. The purpose of using two lamellae was to provide larger areas for investigation and no specific microstructural differences were expected in these two lamellae.

The FPs produced during irradiation consist of relatively heavy elements compared with coating material layers used in TRISO fuel particles. Therefore, the High Angle Annular Dark Field detector in STEM, of which contrast in the image is sensitive to atomic number differences (so-called Z-contrast imaging), was chosen to reveal the distribution of FPs. The compositional analysis of these fine FP precipitates was performed by standardless EDS analysis in STEM mode.

The STEM-EDS analyses were conducted with an FEI Tecnai G2 F30 STEM at the Microscopy and Characterization Suite, Center for Advanced Energy Studies, where low-activity irradiated materials can be examined. Pd, U, and Ag were identified using Pd Kal peak (21.175 keV), U L $\gamma 1$ peak (20.163 keV), and $\mathrm{Ag} \mathrm{K} \alpha 1$ peak (22.162 keV), respectively, to avoid uncertainties associated with peak overlaps. An EDS line scan was used for the qualitative identification of FP using an acquisition time of 10-40 secs/point. Transmission Electron Microscopy images and analysis software were used for quantitative 
EDS analysis, and longer 480 secs/point area analysis was used for quantitative measurements to increase the signal-to-noise ratio.

The preliminary STEM study [4] focused on the SiC-IPyC interlayer area of Sample 6b with selected areas deeper inside the $\mathrm{SiC}$ layer, whereas this study focused on the FP in the SiC layer further from the SiC-IPyC interlayer $(\sim 5 \mu \mathrm{m})$ (Position 1 of Fig. $1[\mathrm{~b}])$. Additionally, Sample 6a was also characterized to produce more information.

\section{RESULTS AND DISCUSSION}

Using High Angle Annular Dark Field imaging and combined EDS measurements, various FP precipitates were identified in the IPyC layer, IPyC-SiC interlayer region, and SiC layer of the TRISO samples (Fig. 1, Fig. 2[a]). These precipitates are categorized based on their size, shape, and location in the microstructure.

\subsection{Micron-sized Precipitates ( $\geq 100 \mathrm{~nm})$}

As shown in Fig. 1, micron-sized precipitates with irregular shape were mainly located at IPyC-SiC interlayer, but some of these precipitates were also observed inside the $\mathrm{SiC}$ and IPyC layers. The size of these precipitates varied from approximately $100 \mathrm{~nm}$ up to $2 \mu \mathrm{m}$, and the precipitates in $\mathrm{SiC}$ and IPyC layers were smaller than those in IPyC-SiC interlayer (Fig. 1 and Fig. 3). Additionally, micron precipitates in the $\mathrm{SiC}$ layer and the $\mathrm{IPyC}-\mathrm{SiC}$ interlayer had sharp protrusions connecting them to $\mathrm{SiC}$ grain boundaries which indicates that their formation may be associated with GB transport of FP. Fig. 2 shows the EDS spectrum of a micron-sized precipitate located at the $\mathrm{SiC}$ layer $\sim 5 \mu \mathrm{m}$ away from the interlayer. These precipitates consist of mainly Pd and U, while other minor FPs, such as $\mathrm{Cs}$, Eu, and Ce, were also identified.

Semi-quantitative compositional analysis was performed on three micron-sized precipitates from different regions (Fig. 3) and results are shown in Table 1. (The \% error displayed in the tables are automatically calculated by the FEI software (100\% error indicates that the specific peak was not identified)) The proportion of $\mathrm{U}, \mathrm{Pd}$, and $\mathrm{Si}$ in the $\mathrm{SiC}$ layer and $\mathrm{SiC}-\mathrm{IPyC}$ interlayer precipitates is close to 1:2:2. This suggests that they may be $\mathrm{UPd}_{2} \mathrm{Si}_{2}$ ternary silicides, as indicated by selected area diffraction pattern in the previous transmission electron microscopy study of another particle from AGR-1 [5]. The carbon concentration in those silicides is similar compared to those in the $\mathrm{SiC}$ matrix whereas the $\mathrm{Si}$ concentration is lower. Micron-sized U-Pd-Si silicides are also identified in the originally Si-free IPyC layer, but have slightly different stoichiometry. Considering that the size of precipitates are larger than the STEM lamella thickness $(\sim 100 \mathrm{~nm})$, and the probe size of STEM is very small $(\sim 1 \mathrm{~nm})$, the influence of the EDS signal from the matrix should be minimal. However, EDS analysis on lighter elements such as $\mathrm{C}$ may not be accurate, and should still be confirmed using atom probe tomography as a more accurate measurement.

The above results may indicate that during the transport of $\mathrm{U}$ and $\mathrm{Pd}$ through the $\mathrm{SiC}$ layer, $\mathrm{SiC}$ was decomposed at some sites. Part of the Si-formed micron-sized $\mathrm{UPd}_{2} \mathrm{Si}_{2}$, and the rest of free the Si could possibly have diffused elsewhere (e.g., IPyC layer) to form other types of silicides. On the other hand, most of the $\mathrm{C}$ remained inside the micron-sized silicides, but the chemical state of this carbon is unclear. E.J. Oliver et al. [15] investigated the Pd transport in single crystalline $\mathrm{SiC}$ and found that $\mathrm{C}$ can form nano-sized precipitates inside Pd silicides. No direct evidence of carbon precipitates was observed in this current study and should be investigated in future studies.

\subsection{Nano-sized Precipitates (5 to $20 \mathrm{~nm}$ )}

Unlike the micron-sized precipitates, which have long been observed by the scanning electron microscopy and transmission electron microscopy studies, [4, 5, 12-14] nano-sized FP precipitates (resulting from a fueled kernel) in neutron irradiated SiC layers for TRISO coated particles were not seen until STEM was introduced as an advanced characterization technique [4]. Ion implanted out-of-pile studies on $\mathrm{SiC}$ 
showed nano precipitation of metallic products ([21.22]) and although contributed towards understanding of some microstructural effects, could not fully simulate the transport behavior of $\mathrm{Ag}$ and $\mathrm{Pd}$ behavior in intact TRISO fuel particles. Nearly spherical-shaped nano-precipitates, $5 \mathrm{~nm}$ to $20 \mathrm{~nm}$ in size, were identified mainly located inside the $\mathrm{SiC}$ grains at the $\mathrm{SiC}$-IPyC interlayer and further inside the $\mathrm{SiC}$ layer (Fig. 4[a]). Most of these nano-precipitates were identified to be Pd-rich with no detectable Ag and $\mathrm{U}$ (Fig. 4[c]), which is consistent with the previous work [4]. Further examination in this study showed that a small amount of Ag was detected in one EDS site (Fig. 4[b]). Fig. 4(b) shows an example of the Pd-Ag nano-sized particle, which is found in the $\mathrm{SiC}$ layer $\sim 5 \mu \mathrm{m}$ away from the interlayer. The EDS spectrum clearly showed peaks corresponding to $\mathrm{Pd}$ and $\mathrm{Ag}$. Among 10 nano-sized precipitates evaluated in this study, only two contained Ag. These Ag-Pd containing nano-precipitates should be further investigated to determine if they are intergranular or intragranular.

The semi-quantitative analysis results of selected nano-sized precipitates are shown in Table 2. The Si content in precipitates is higher, whereas $\mathrm{C}$ content is lower than in the $\mathrm{SiC}$ matrix, indicating the precipitates to be FP silicides. The concentration of FP measured in nano-sized precipitates is much smaller than $\mathrm{Si}$ or $\mathrm{C}$. This is because the collected EDS signal emanates mainly from $\mathrm{SiC}$ matrix $(\sim 100 \mathrm{~nm}$ size, comparable to sample thickness) rather than from small size of precipitates $(<20 \mathrm{~nm})$. The influence of precipitates size on the EDS results is schematically shown in Fig. 5 as a typical example. For nano-sized precipitates (Fig. 5[a]), Pd enrichment can be observed inside the precipitate, but there is no change in $\mathrm{C}$ and Si concentration as shown by the EDS spectra and as indicated in Table 2. On the contrary, the Si counts were clearly lower in the micron precipitate than in the matrix (see EDS line profile in Fig. $5[\mathrm{~b}]$ ), but the $\mathrm{C}$ counts remained the same, consistent with quantitative results shown in Table 1.

\subsection{GB precipitates (Width $<5 \mathrm{~nm}$ ) and Triple Junction Precipitates (10 to $20 \mathrm{~nm}$ )}

Nano-sized FP at triple junctions and boundaries of SiC grain was revealed by STEM-High Angle Annular Dark Field imaging (Fig. 6 and Fig. 7). These triple junction precipitates are connected by hairline-shaped GB precipitates. In the previous study [4], these intergranular precipitates were found to be either Pd-rich (identified up to $4 \mu \mathrm{m}$ from SiC-IPyC interlayer) or Ag-rich (up to $0.5 \mu \mathrm{m}$ from the interlayer). This work confirmed the results of the previous study by analyzing more areas.

Pd-rich intergranular precipitates were identified up to $5 \mu \mathrm{m}$ from SiC-IPyC interlayer as shown in Fig. 5(a) and Fig. 6. Quantitative results in Table 3 suggest the Pd-rich triple junction precipitates to be Pd silicides with no detectable $\mathrm{U}$ or Ag. Variation in Pd concentration may be influenced by the matrix signals, the extent of which depends on different precipitates' sizes.

Ag-rich intergranular precipitates were identified up to $1.5 \mu \mathrm{m}$ from SiC-IPyC interlayer (Fig. 7) providing evidence of $\mathrm{Ag}$ can transport along $\mathrm{SiC}$ grain boundaries. EDS spectrum shows that no $\mathrm{U}$ and Pd exist inside the Ag-rich precipitates, but a small amount of $\mathrm{Cd}$ was identified.

\subsection{Network of Ultra Fine Precipitates ( $<5 \mathrm{~nm})$}

A network of ultra-fine precipitates (size $<5 \mathrm{~nm}$ ) was observed for the first time inside the $\mathrm{SiC}$ grains adjacent to a micron-sized precipitate in the SiC layer (Fig. 2 and Fig. 8). The EDS results indicate these precipitates to be U-rich along with other minor FP such as Ba, and Ru. Mechanism(s) of formation for this honeycomb-shaped precipitate network is unclear; however, one assumption is that they may be related to a void or dislocation network inside $\mathrm{SiC}$ grains. 
Table 1. Quantitative EDS results showing the composition of different micron-sized precipitates shown on Fig. 3.

\begin{tabular}{|c|c|c|c|c|c|c|c|c|}
\hline & \multicolumn{2}{|c}{ SiC Matrix } & \multicolumn{2}{c|}{ M1 } & \multicolumn{3}{c|}{ M2 } & \multicolumn{3}{c|}{ M3 } \\
\cline { 2 - 10 } Elements & $\begin{array}{c}\text { Concentration } \\
\text { (at.\%) }\end{array}$ & $\begin{array}{c}\text { Error } \\
\text { (\%) }\end{array}$ & $\begin{array}{c}\text { Concentration } \\
\text { (at.\%) }\end{array}$ & Error (\%) & $\begin{array}{c}\text { Concentration } \\
\text { (at.\%) }\end{array}$ & Error (\%) & $\begin{array}{c}\text { Concent. } \\
\text { (at.\%) }\end{array}$ & Error (\%) \\
\hline C(K) & 47.14 & 1.10 & 46.93 & 0.12 & 48.39 & 0.20 & 58.33 & 0.25 \\
\hline Si(K) & 52.79 & 0.89 & 21.69 & 0.05 & 20.36 & 0.08 & 12.21 & 0.08 \\
\hline Pd(K) & 0.00 & 100.00 & 21.08 & 0.20 & 20.86 & 0.32 & 17.85 & 0.31 \\
\hline $\mathbf{U}(\mathbf{L})$ & 0.07 & 0.11 & 10.30 & 0.24 & 10.39 & 0.37 & 11.61 & 0.39 \\
\hline
\end{tabular}

Table 2. Quantitative EDS results showing the composition of Pd-Ag (Fig. 4[b]) and Pd-rich (Fig. 4[c]) nano-sized spherical precipitates.

\begin{tabular}{|c|c|c|c|c|c|c|c|c|}
\hline \multirow[b]{2}{*}{ Elements } & \multicolumn{2}{|c|}{ SiC Matrix } & \multicolumn{2}{|c|}{ S1 } & \multicolumn{2}{|l|}{ S2 } & \multicolumn{2}{|c|}{ S3 } \\
\hline & $\begin{array}{c}\text { Concentration } \\
\text { (at.\%) }\end{array}$ & Error (\%) & $\begin{array}{c}\text { Concentration } \\
\text { (at.\%) }\end{array}$ & Error (\%) & $\begin{array}{c}\text { Concentration } \\
\text { (at.\%) }\end{array}$ & Error (\%) & Error (at.\%) & Error (\%) \\
\hline$C(K)$ & 47.14 & 1.10 & 31.30 & 0.41 & 26.21 & 0.34 & 32.37 & 0.38 \\
\hline $\mathrm{Si}(\mathrm{K})$ & 52.79 & 0.89 & 66.36 & 0.41 & 66.51 & 0.37 & 62.38 & 0.36 \\
\hline $\mathrm{Pd}(\mathrm{K})$ & 0.00 & 100.00 & 1.88 & 0.26 & 7.04 & 0.50 & 5.25 & 0.98 \\
\hline $\mathrm{Ag}(\mathrm{K})$ & 0.00 & 100.00 & 0.46 & 0.17 & 0.06 & 0.11 & 0.00 & 100.00 \\
\hline $\mathrm{U}(\mathrm{L})$ & 0.07 & 0.11 & 0.00 & 100.00 & 0.18 & 0.13 & 0.00 & 100.00 \\
\hline
\end{tabular}

Table 3. Quantitative EDS results showing the composition of three Pd-rich triple junction precipitates shown on Fig. 6.

\begin{tabular}{|c|c|c|c|c|c|c|c|c|}
\hline & \multicolumn{2}{|c|}{ SiC Matrix } & \multicolumn{2}{c|}{ T1 } & \multicolumn{2}{c|}{ T2 } & \multicolumn{2}{c|}{ T3 } \\
\cline { 2 - 10 } Elements & $\begin{array}{c}\text { Concentration } \\
\text { (at.\%) }\end{array}$ & Error (\%) & $\begin{array}{c}\text { Concentration } \\
\text { (at.\%) }\end{array}$ & Error (\%) & $\begin{array}{c}\text { Concentration } \\
\text { (at.\%) }\end{array}$ & Error (\%) & $\begin{array}{c}\text { Tat.\%) } \\
\text { Error (\%) }\end{array}$ \\
\hline C(K) & 47.14 & 1.10 & 41.13 & 0.35 & 36.0 & 0.36 & 33.43 & 0.26 \\
\hline Si(K) & 52.79 & 0.89 & 51.40 & 0.27 & 58.98 & 0.33 & 55.75 & 0.92 \\
\hline Pd(K) & 0.00 & 100.00 & 7.47 & 0.34 & 4.83 & 0.35 & 10.77 & 0.98 \\
\hline $\mathbf{U}(\mathrm{L})$ & 0.07 & 0.11 & 0.00 & 100.00 & 0.19 & 0.13 & 0.05 & 0.09 \\
\hline
\end{tabular}

\subsection{Transport Mechanism of Different Fission Products (FPs)}

The FP precipitates observed in this work are within the inner part of TRISO fuel particle (up to $5 \mu \mathrm{m}$ from the SiC-IPyC interlayer); therefore, it is hard to conclude if these precipitates account for the release of certain FPs. However, the identification of these precipitates indicates possible active transport mechanisms for different FPs.

Pd containing precipitates were historically found to aggregate at the SiC-IPyC interlayer and can corrode $\mathrm{SiC}$ layer $[13,14]$. No significant Pd corrosion was observed in as-irradiated AGR-1 particles, but scanning electron microscopy-WDS examination [5,9] showed numerous Pd precipitates at the SiC-IPyC interlayer as well as a distribution of Pd precipitates inside SiC layer. The better resolution of STEM reveals that these precipitates have sharp protrusions that are connected by $\mathrm{SiC}$ grain boundaries, as shown in Section 3.1, which indicate that they are likely formed by a GB transport mechanism.

Simulated TRISO particle experiment by Pearson et al. [12] and Pd-polycrystalline SiC diffusion experiment by Olivier et al. [15] suggest that $\mathrm{Pd}$ can react with $\mathrm{SiC}$ to form $\mathrm{Pd}$-silicide nodules at $\mathrm{SiC}$ grain boundaries, and those nodules can then migrate along grain boundaries by dissolving $\mathrm{SiC}$ at the leading edge and forming $\mathrm{SiC}$ at the tailing edge. Other metallic products, such as $\mathrm{U}$ [12] and $\mathrm{Ag}$ [16], 
can then dissolve in those Pd-silicide nodules and transport the products together along the grain boundaries. However, it should be noted that localized Pd corrosion has been found in neutron irradiated particles with breached buffer and pyrolytic carbon [17] but no significant Pd corrosion was found in a large majority of coated particles of the AGR1 experiment which exhibit Ag and Pd releases. Clarification is needed to differentiate between the potential mechanistic differences. The micron-sized Pd precipitates at grain boundaries of $\mathrm{SiC}$ layer in this study are likely to form and migrate by the same mechanism.

While the micron-sized precipitate has stoichiometry close to $\mathrm{Pd}_{2} \mathrm{Si}_{2} \mathrm{U}$ (Table 1), no $\mathrm{U}$ was identified in the nano-sized hair-line GB precipitates or triple junction precipitates. Those nano-sized GB and triple junction $\mathrm{Pd}$ precipitates have also been observed in $\mathrm{Pd}-\mathrm{SiC}$ surrogate diffusion experiment, and their formation may be associated with a more rapid liquid state reaction [15]. The melting point of $\mathrm{Pd}_{2} \mathrm{Si}_{2} \mathrm{U}$ $\left(\sim 1500^{\circ} \mathrm{C}\right)[18]$ is higher than the melting point of Pd-silicides (from 960 to $1330^{\circ} \mathrm{C}$ depending on stoichiometry) [19] and the average fuel particle temperature during the Compact 6-3-2 irradiation $\left(1070^{\circ} \mathrm{C}\right)[5]$. Therefore, $\mathrm{U}$ transports along $\mathrm{GB}$ only by "mobile nodule" formation without forming nano-sized intergranular precipitates.

Besides the intergranular precipitates, nano-sized spherical Pd precipitates and ultra-fine U precipitates observed within the $\mathrm{SiC}$ grains also suggest possible intragranular transport mechanisms for $\mathrm{Pd}$ and $\mathrm{U}$. The U precipitates distribute in a honeycomb-like network (Fig. 2[a] and Fig. 8) inside SiC grain, which may be related with voids or dislocation network produced by neutron radiation [22]. The Pd spherical precipitates were not observed in the surrogate experiment [15], which may also associate with radiation effects. However, the nature of how radiation facilitates the formation and migration of those intergranular precipitates still requires understanding.

Micro-crack vapor release [6] and GB diffusion [7-11] has been proposed as two competing hypotheses. Another study suggests Ag alone cannot transport through $\mathrm{SiC}$, but the existing Pd can greatly assist Ag transport by forming Pd-Ag-Si nodules along $\mathrm{SiC}$ grain boundaries [16]. In this study, $\mathrm{Ag}$ was found in $\mathrm{SiC}$ grain boundaries and triple junctions up to $1.5 \mu \mathrm{m}$ from the $\mathrm{SiC}-\mathrm{IPyC}$ interlayer, providing direct evidence of $\mathrm{Ag}$ GB diffusion. Compared with $\mathrm{Pd}$ rich grain boundaries and triple junctions, which were identified up to $5 \mu \mathrm{m}$ in $\mathrm{SiC}$ layer from SiC-IPyC interlayer, the intergranular Ag was identified within a shorter range. This may imply that Ag GB transport is slower than Pd; however, more GB precipitates need to be examined to confirm this. It is worth noting that in these areas of studying, no Pd was identified in Ag-rich grain boundaries and triple junctions and no Ag was identified inside the micronsized Pd-U-Si precipitates. This may suggests that the Pd assisted Ag transport through "mobile Pdsilicide nodules" as proposed in [12] and [16] is not likely to be the main mechanism for Ag GB transport. However, it should be noted that atomic migration along the grain boundaries, below the STEM and EDS detection limits, is possible and likely. From this study, it seems that $\mathrm{Pd}$ is not required for $\mathrm{Ag}$ intergranular transport. The single instance where an Ag-Pd nano-sized precipitate was found inside the $\mathrm{SiC}$ grains suggests a possible Pd-assisted intragranular transport mechanism for Ag. Similar to the intragranular Pd precipitates, Ag-Pd intragranular precipitates were not observed in the surrogate experiment [16], indicating a possible relation with radiation effects. Recent work by Coward et al., [22] on ion-irradiated work, also reported a potential correlation of $\mathrm{Ag}$ transport in $\beta$-SiC grains with void formation. This needs to be explored in further neutron irradiated TRISO coated particle high resolution transmission electron microscopy. Small amounts of Cd were also seen in the Ag-rich GB precipitates and triple junction precipitates, which suggest that it can transport with Ag by intergranular mechanism.

\section{CONCLUSIONS}

Previous studies $[4,20]$ have illustrated the potential of STEM-EDS method to identify Ag at the SiCIPyC interlayer in a neutron irradiated TRISO fuel particle during postirradiation examination. In the present study, we further examined FP precipitates inside SiC layer $(0.5 \mu \mathrm{m}$ to $5 \mu \mathrm{m}$ from the interlayer), along with a quantitative assessment of size, shape, preferential location, and composition of those FP precipitates 
$\mathrm{Ag}$ was found in $\mathrm{SiC}$ grain boundaries and triple junctions up to $1.5 \mu \mathrm{m}$ from the $\mathrm{SiC}-\mathrm{IPyC}$ interlayer, providing direct evidence of $\mathrm{Ag}$ GB diffusion. No Pd was found in those nano-sized Ag GB and triple junction precipitates, which suggests that Pd may not be required for $\mathrm{Ag} \mathrm{GB}$ transport. The co-existence of Cd with Ag in triple points reported previously [4] was confirmed by the present study.

The presence of Pd rich nano-sized intragranular precipitates previously reported by van Rooyen et al. [4] was further investigated. In a single instance an $\mathrm{Ag}-\mathrm{Pd}$ nano-sized precipitate was found inside the $\mathrm{SiC}$ grains, which suggests a possible Pd-assisted intragranular transport mechanism for Ag. Further highresolution STEM work is needed to explore the intragranular Ag-Pd precipitate formation and potential correlation with void formation. Those nano-sized precipitates were not observed in the surrogate $\mathrm{Pd} / \mathrm{Ag}-$ $\mathrm{SiC}$ diffusion experiments $[15,16]$, thus the precipitates may be associated with neutron radiation effects. More precipitates need to be examined to understand the nature of their formation and migration.

Honeycomb shape U-rich FP networks inside $\mathrm{SiC}$ grain were found near a micron precipitate in SiC about $\sim 5 \mu \mathrm{m}$ from the SiC-IPyC interlayer, indicating a possible intragranular transport path for uranium. This is the first work showing such a finding in irradiated $\mathrm{SiC}$, which may be related to void or dislocation network inside $\mathrm{SiC}$ grains.

Preliminary quantitative analysis indicated the micron-sized precipitates to be $\mathrm{Pd}_{2} \mathrm{Si}_{2} \mathrm{U}$ with carbon existing inside these precipitates. The nano-sized precipitates are also likely to be FP-silicides considering their high Si content compared to the SiC matrix. However, the quantitative results for nano-sized precipitates are greatly influenced by the background $\mathrm{SiC}$ matrix, which makes it impossible to obtain the accurate chemical compositions.

\section{ACKNOWLEDGEMENT}

This work was sponsored by the U.S. Department of Energy, Office of Nuclear Energy, under the Department of Energy Idaho Operations Office Contract DE-AC07-05ID14517, as part of the Very High Temperature Reactor Development Program and as part of an Advanced Test Reactor National Scientific User Facility Experiment. James Madden is acknowledged for the focused ion beam sample preparation. Paul Demkowicz and David Petti are thanked for the review of this paper.

\section{REFERENCES}

[1] D. Petti, J. Maki, J. Hunn, P. Pappano, C. Barnes, J. Saurwein, S. Nagley, et al., The DOE advance gas reactor fuel development and qualification program, JOM-US 62 (9) (2010) 62-66.

[2] H. Nabielek, P.E. Brown, P. Offermann, Silver Release from Coated Particle Fuel, Nucl. Technol. 35

(2) (1977) 483-493.

[3] P.A. Demkowicz, J.D. Hunn, R.N. Morris, J.M. Harp, P.L. Winston, C.A. Baldwin, F.

C. Montgomery, Preliminary results of post-irradiation examination of the AGR-1 TRISO fuel compacts, Paper HTR2012-3-021, Proceedings of the HTR 2012, Tokyo, Japan, October 28-November 1, 2012.

[4] I.J. van Rooyen, T.M. Lillo, Y.Q. Wu, Identification of silver and palladium in irradiated TRISO coated particles of the AGR-1 experiment, J. Nucl. Mater. 446 (2014) 178-186.

[5] I.J. van Rooyen, D.E. Janney, B.D. Miller, P.A. Demkowicz, J. Riesterer, Electron microscopic evaluation and fission product identification of irradiated TRISO coated particles from the AGR-1 experiment, a preliminary review, Nucl. Eng. and Des. 271 (2014) 114-122.

[6] H.J. MacLean, R.G. Ballinger, L.E. Kolaya, S.A. Simonson, N. Lewis, M.E. Hanson, The effect of annealing at $1500^{\circ} \mathrm{C}$ on migration and release of ion implanted silver in CVD silicon carbide, J. Nucl. Mater. 357 (2006) 31-47.

[7] E. Friedland, J.B. Malherbe, N.G. van der Berg, T. Hlatshwayo, A.J. Botha, E. Wendler, W. Wesch, Study of silver diffusion in silicon carbide, J. Nucl. Mater. 389 (2) (2009) 326-331. 
[8] E. Lopez-Honorato, D.X. Yang, J. Tan, P.J. Meadows, P. Xiaow, Silver diffusion in coated fuel particles, J. Am. Ceram. Soc. 93 (10) (2010) 3076-3079.

[9] T. J. Gerczak, B. Leng, K. Sridharan, J. L. J. Hunter, A. J. Giordani, T. R. Allen, "Observations of Ag Diffusion in Ion Implanted SiC", Journal of Nuclear Materials 461 (2015) 314-324, http://dx.doi.org/10.1016/j.jnucmat.2015.03.027

[10] D. Shrader, S.M. Khalil, T. Gerczak, T.R. Allen, A.J. Heim, I. Szlufarska, D. Morgan, Ag diffusion in cubic silicon carbide, J. Nucl. Mater. 408 (3) (2011) 257-271.

[11] S. Khalil, N. Swaminathan, D. Schrader, A.J. Heim, D.D. Morgan, I. Szlufarska, Diffusion of Ag along $\Sigma 3$ grain boundaries in 3C-SiC, Phys. Rev. B 84 (2011) 214104.

[12] R. L. Pearson, R. J. Lauf, T. B. Lindemer, The Interaction of Palladium, the Rare Earths, and Silver with Silicon Carbide in HTGR Fuel Particles, Oak Ridge National Laboratory, Oak Ridge Report ORNL/TM-8059 (1982).

[13] D.A. Petti, J. Buongiorno, J.T. Maki, R.R. Hobbins, GK Miller, Key differences in the fabrication, irradiation and high temperature accident testing of U.S. and German TRISO-coated particle fuel, and their implications on fuel performance, Nucl. Eng. Des. 222 (2003) 281-297.

[14] T.N. Tiegs, Fission product Pd-SiC interaction irradiated coated particle fuels, Nucl. Technol. 57 (1982) 389.

[15] E.J. Olivier, J.H. Neethling, Palladium transport in SiC, Nucl. Eng. Des. 244 (2012) 25-33.

[16] E.J. Olivier, J.H. Neethling, The role of Pd in the transport of Ag in SiC, J. Nucl. Mater. 432 (2013) $252-260$.

[17] J.D. Hunn, C.A. Baldwin, T.J. Gerczak, F.C. Montgomery, R.N. Morris, C.M. Silva, P.A. Demkowicz, et al., Detection and analysis of particles with failed SiC in AGR-1 fuel compacts, Paper HTR2014-31254, Proc. HTR2014, Weihai, China, October 27-31, 2014.

[18] A.A. Menovsky, A.C. Moleman, G.E. Snel, T.J. Gortenmulder, H.J. Tan, T.T.M. Palstra, Crystal growth and characterization of $\mathrm{MT}_{2} \mathrm{Si}_{2}$ ternary intermetallics $(\mathrm{M}=\mathrm{U}, \mathrm{RE}$ and $\mathrm{T}=3 \mathrm{~d}, 4 \mathrm{~d}, 5 \mathrm{~d}$ transition metals), J. Cryst. Growth 79 (1) (1986) 316-321.

[19] J.W. Mayer, K.N. Tu, Analysis of thin-film structures with nuclear backscattering and x-ray diffraction, J. Vac. Sci. Technol. 11 (1) (1974) 86-93.

[20] I.J. van Rooyen, Y.Q. Wu, T.M. Lillo, T.L. Trowbridge, J.M. Madden, D. Goran, Advanced electron microscopic techniques applied to the characterization of irradiation effects and fission product identification of irradiated TRISO coated particles from the AGR-1 experiment, Global conference, September 29, 2013.

[21] Ute Kaiser, Nanocrystal formation in hexagonal $\mathrm{SiC}$ after $\mathrm{Ge}+$ ion implantation, Journal of electron Microscopy 50 (3) (2001) 251-263

[22] Robert A. Coward, Christopher R. Winkler, William A. Hanson, Michael L. Jablonski, Mitra L. Taheri, Transmission electron microscopy investigation of Ag diffusion mechanisms in $\beta$-SiC, J. Nucl. Mater. 457 (2015) 298-303. 


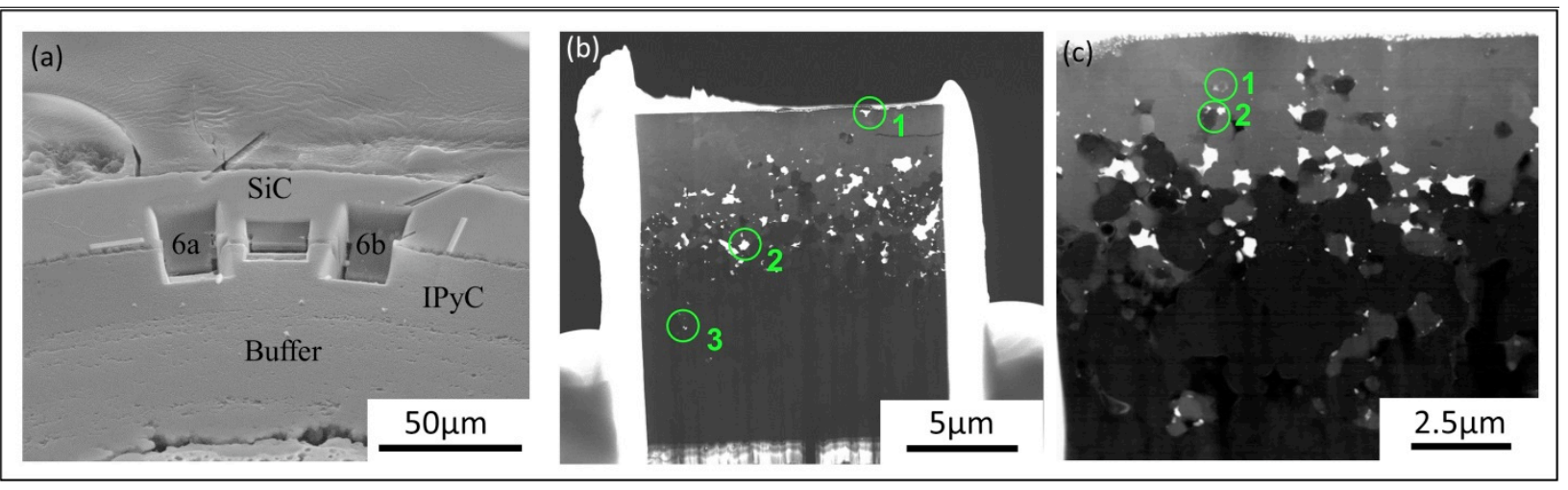

Fig. 1. Images showing (a)positions in a post irradiated TRISO fuel particle from where STEM lamellae were fabricated, (b)positions investigated in lamella 6b(Position 1:SiC layer, Position 2: SiC-IPyC interlayer and Position 3:IPyC layer) and (c) positions investigated in lamella 6a (Positions 1 and 2: SiC layer).
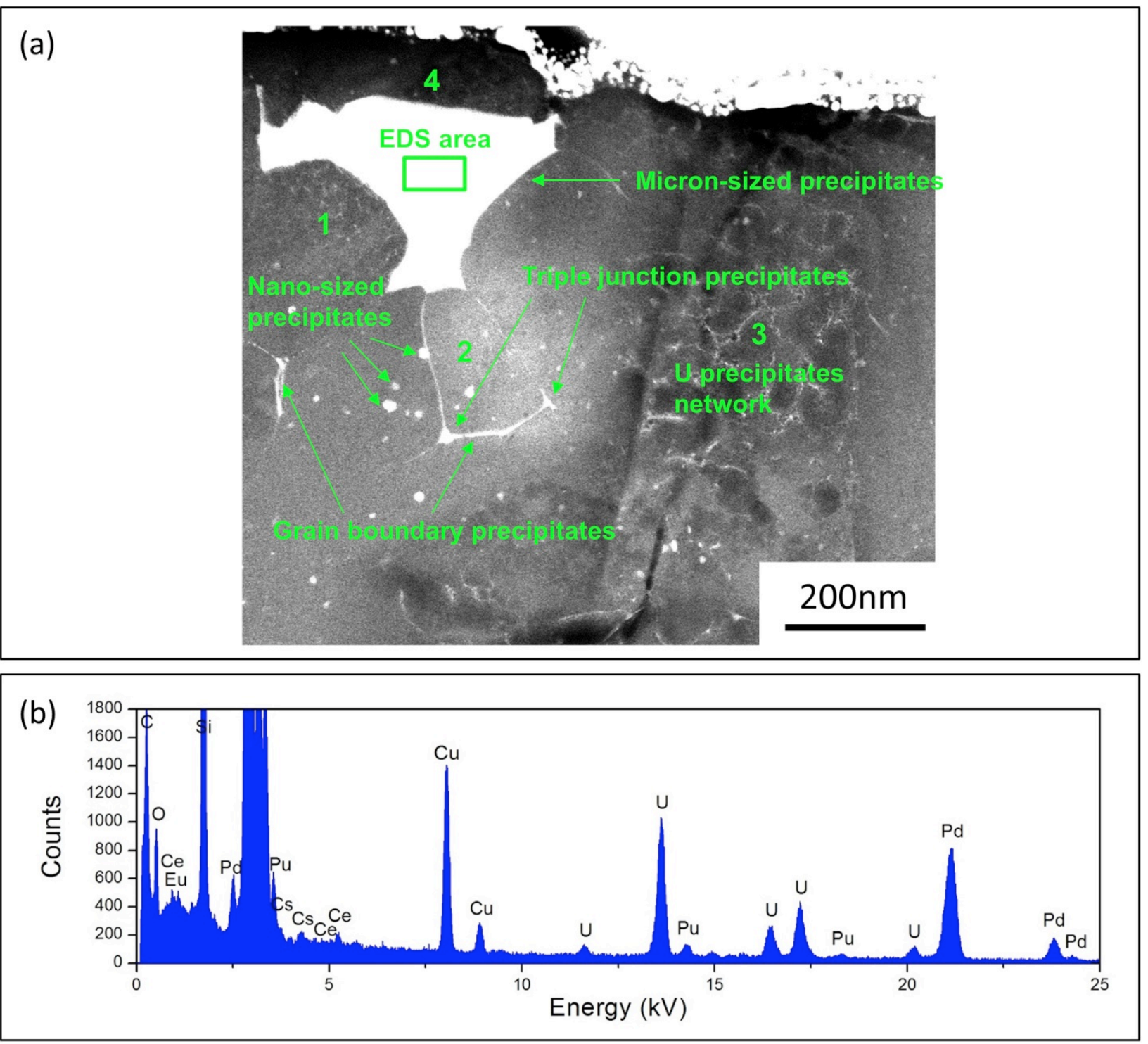
Fig. 2 (a) Distribution of various FP precipitates in the SiC layer $\sim 5$ um from SiC-IPyC interlayer of sample $6 \mathrm{~b}$ (position1 in Fig. 1[b]), numbers are used for marking different regions which will be shown in higher magnification in other figures, and (b) EDS area scanning spectrum inside the micron-sized precipitate (within the green box) ( $\mathrm{Cu}$ is an artifact from transmission electron microscopy grid).

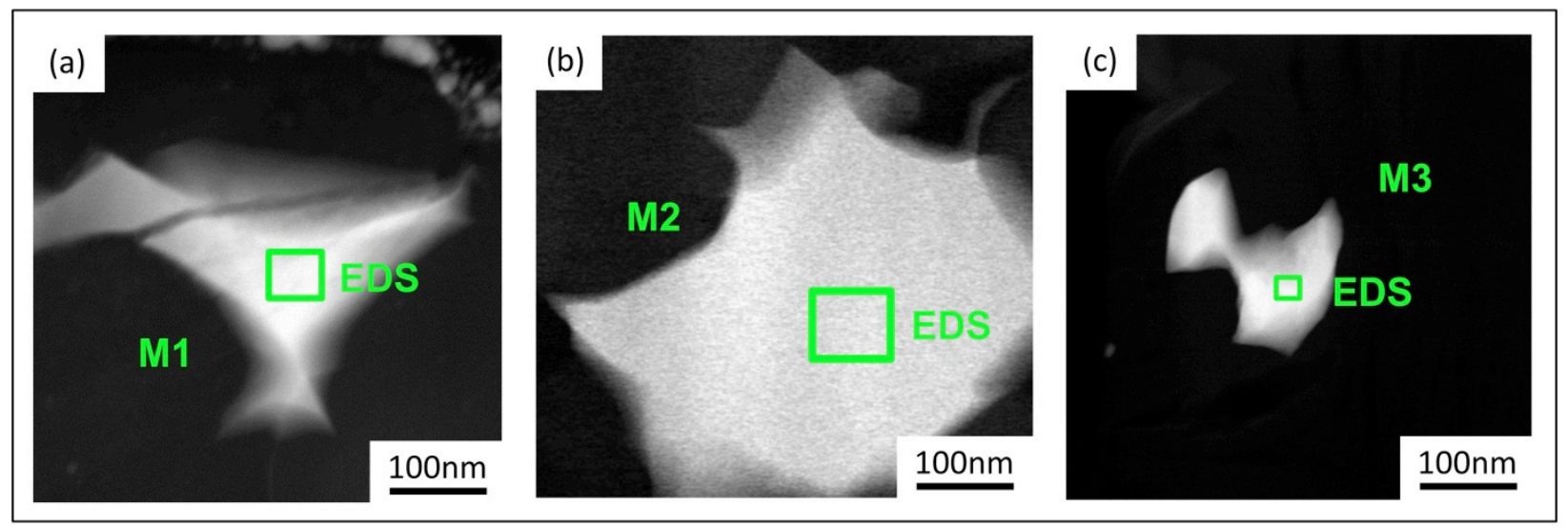

Fig. 3. Micron-sized ( $\geq 100 \mathrm{~nm}$ ) precipitates identified at (a)SiC layer (b)SiC-IPyC interlayer and (c)IPyC layer, green boxes are regions of EDS quantitative analysis.

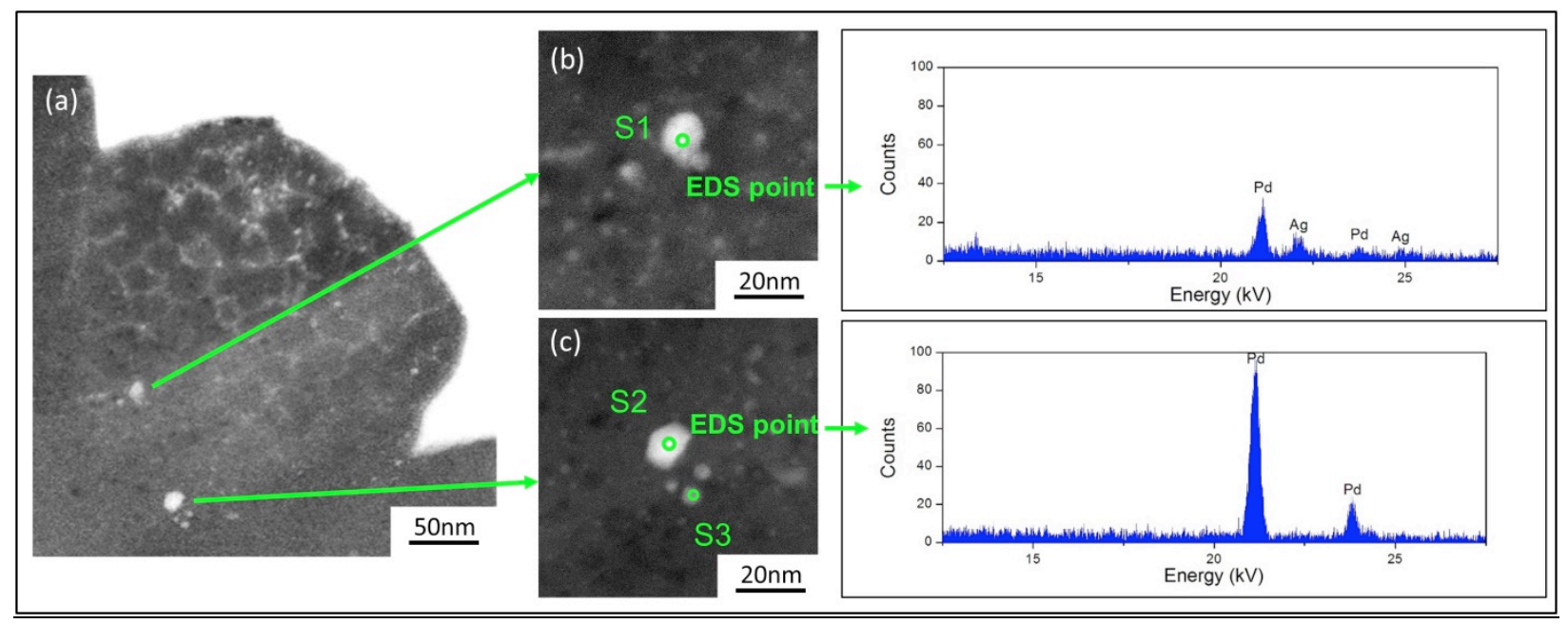

Fig. 4. (a) Different types of nano-precipitates identified inside a SiC grain (position1 in Fig. 2[a]), (b) EDS spectrum indicates S1 is a Pd-Ag precipitate and (c) EDS spectrum indicates S2 is a Pd-rich precipitate. 


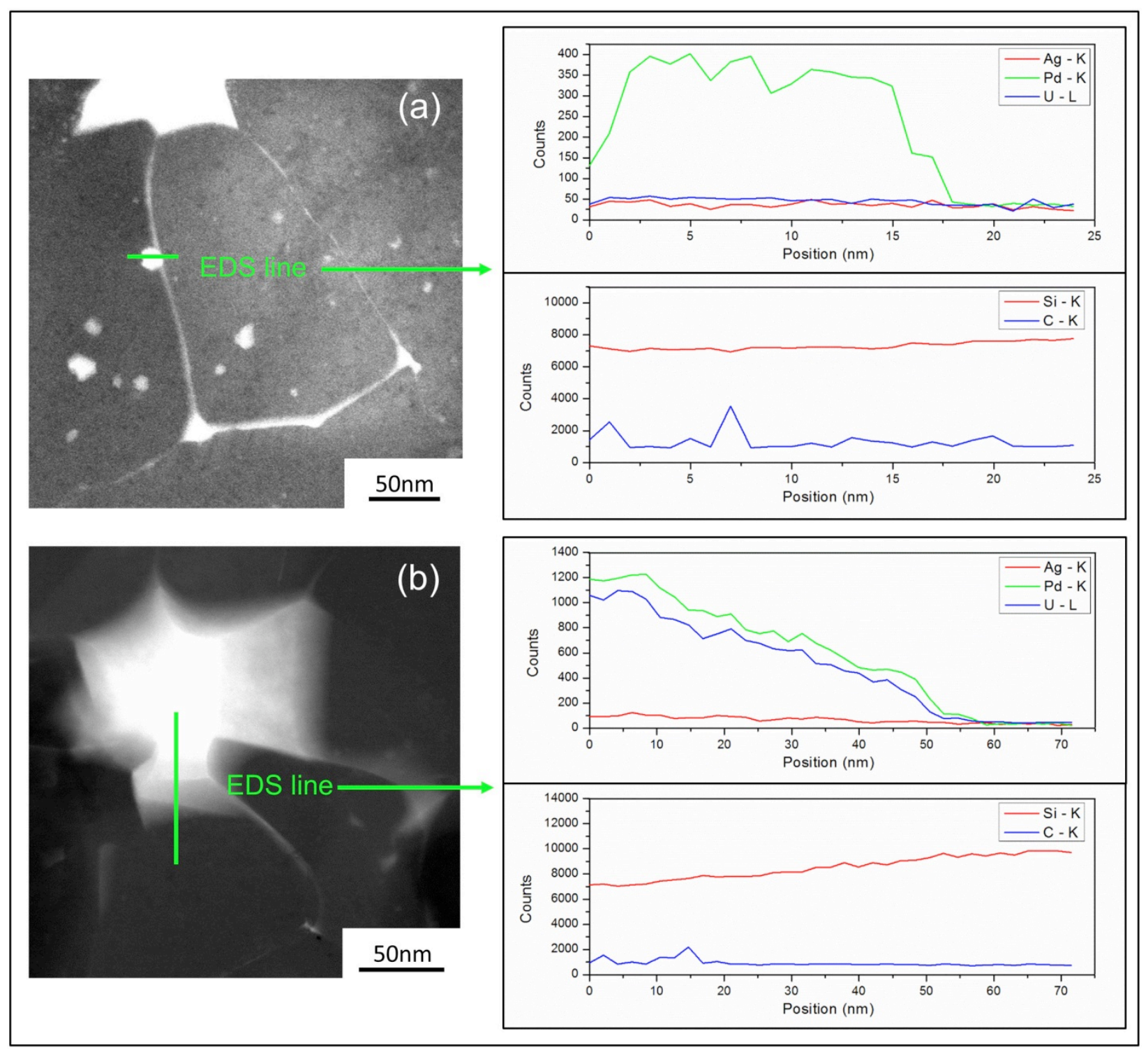

Fig. 5. Typical EDS line scan profiles of Si and C across (a) a nano-sized precipitate and (b) a micronsized precipitate. 


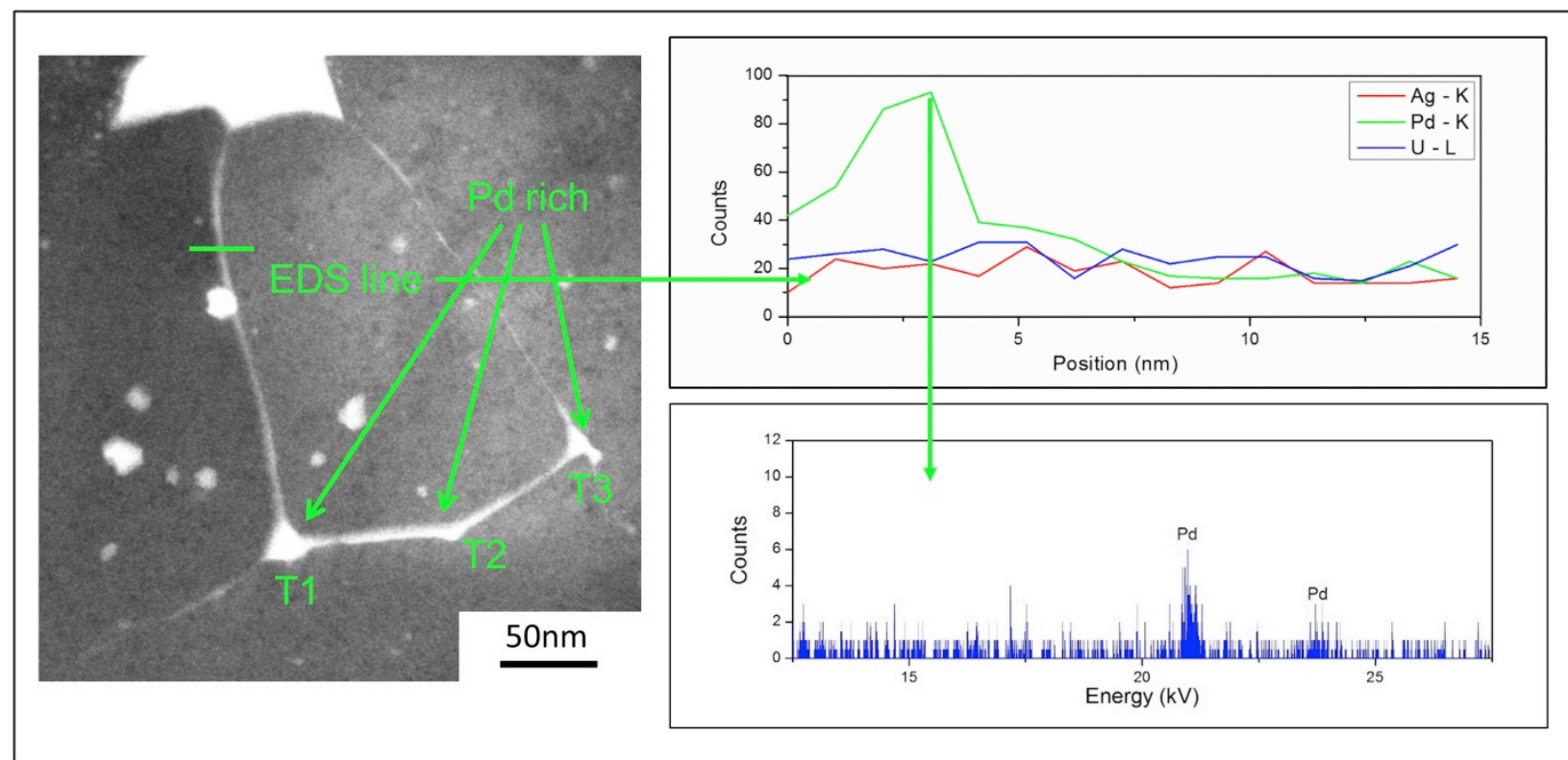

Fig. 6. High magnification image of position.2 in Fig. 2(a), showing Pd-rich GB precipitates and triple junction precipitates.

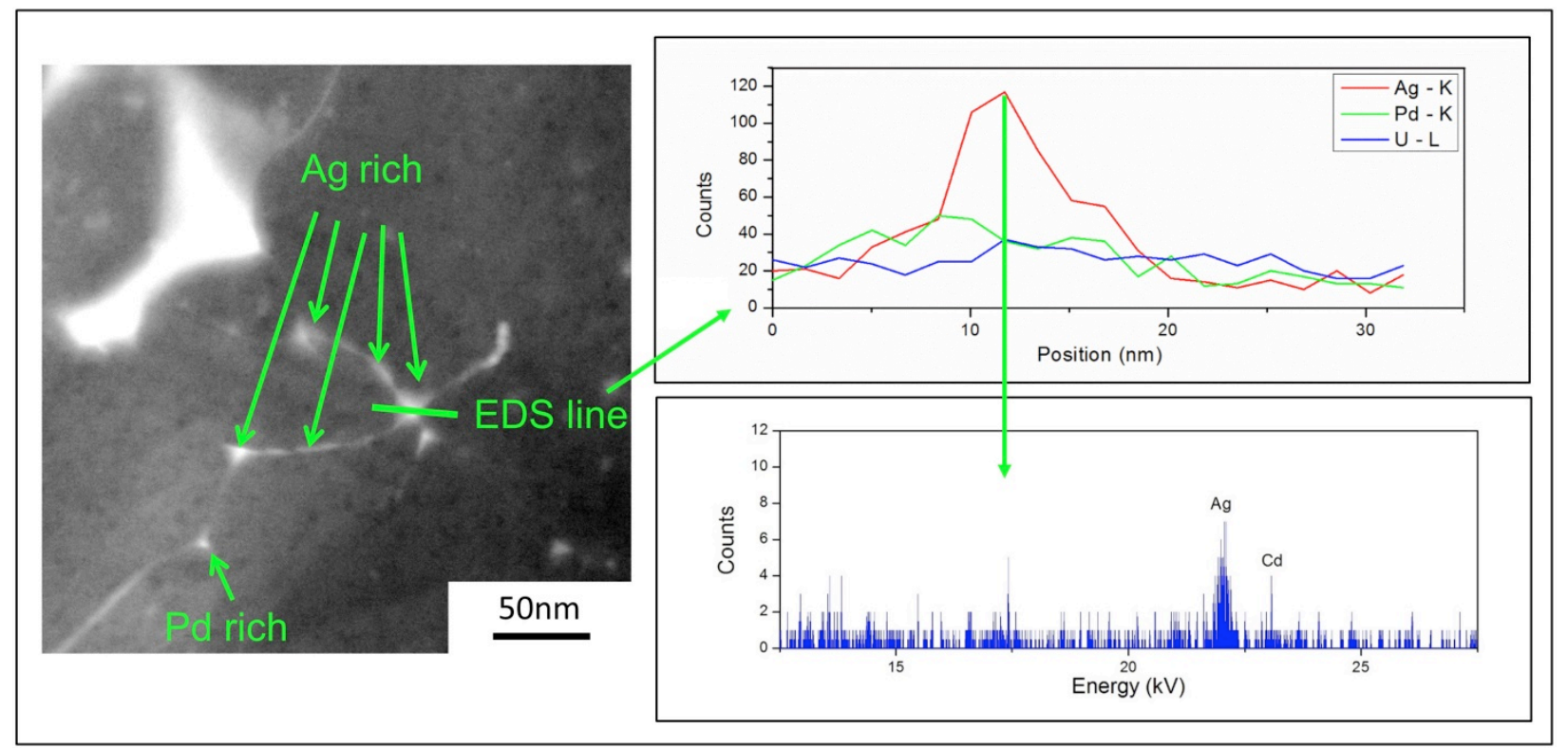

Fig. 7. Ag-rich GB and triple junction precipitates in SiC layer of sample 6a, 1.5 um from SiC-IPyC interlayer (position 1 in Fig. 1[c]). 


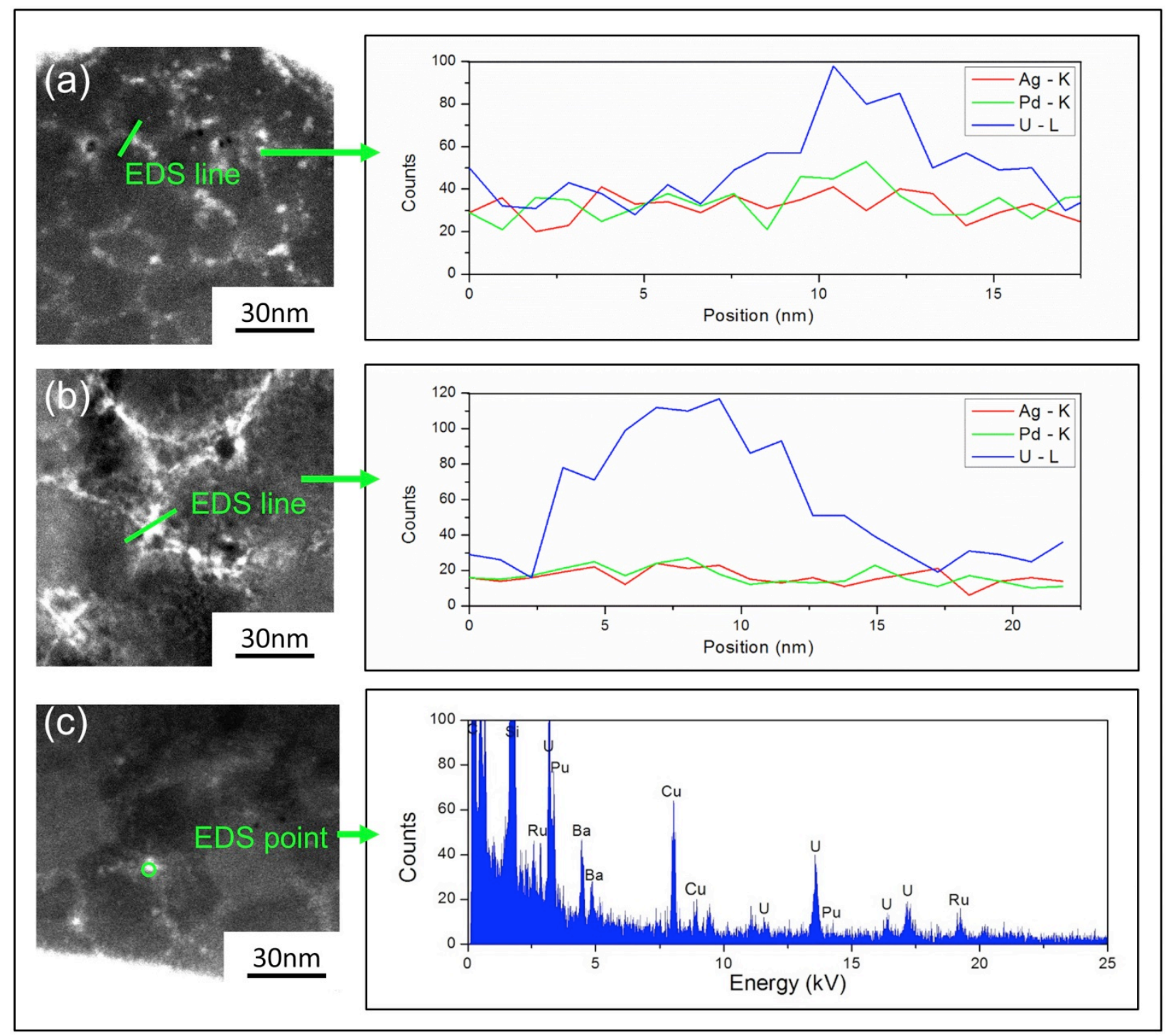

Fig. 8. U-rich precipitates networks at (a) position.1, (b) position.3 and (c) position.4 in Fig. 2(a). 